\title{
COMPARISON OF GNSS INDICES, IONOSONDES AND ALL-SKY IMAGERS IN MONITORING THE IONOSPHERE IN BRAZIL DURING QUIET AND DISTURBED DAYS
}

\author{
Ana Lucia Christovam de Souza ${ }^{1}$ - ORCID: 0000-0002-2677-4982 \\ Paulo de Oliveira Camargo 1, 2 - ORCID: 0000-0001-7648-1291 \\ ${ }^{1}$ Universidade Estadual Paulista, Faculdade de Ciências e Tecnologia, Programa de Pós-Graduação em \\ Ciências Cartográficas, Presidente Prudente, SP, Brasil \\ ${ }^{2}$ Universidade Estadual Paulista, Faculdade de Ciências e Tecnologia, Departamento de Cartografia, \\ Presidente Prudente, SP, Brasil \\ E-mail: a.lucia4@hotmail.com, paulo.camargo@unesp.br
}

Received in $19^{\text {th }}$ November 2018

Accepted in $11^{\text {th }}$ July 2019

\section{Abstract:}

Measurements from the Global Navigation Satellite System (GNSS) have become a leading data source for ionospheric studies. Different technologies are used to monitor the ionospheric layer. It is possible to carry out this monitoring using GNSS networks through the indices of ionospheric irregularities, as well as through ionosondes and imagers. It has therefore become essential to correlate these forms of monitoring, presenting their advantages and disadvantages. With this in mind, the aim of this work was to perform an analysis of the behavior of the ionosphere in the Brazilian region through the ionospheric irregularity indices, along with ionosonde information and all-sky optical imagers, for a day of high solar activity (1 March 2014) and a day of low activity (12 April 2015). The results of each monitoring technique were compatible for the different scenarios, showing a moderate and positive correlation between the irregularity indices $\left(F_{P}\right)$ and ionosonde parameter. The imagers perform measures of greater spatial extent, however, they need favorable meteorological conditions. The ionosondes present a greater diagnostic capacity of the ionosphere but they are fewer in number than the imagers. The GNSS networks become ionosphere monitoring stations through the irregularity indices, enabling an increase in spatial resolution and a better understanding of ionospheric phenomena in the Brazilian territory.

Keywords: Ionospheric irregularities; lonosonde; Imagers;

How to cite this article: SOUZA, A. L. C. and CAMARGO, P. L. Comparison of GNSS Indices, lonosondes and All-Sky Imagers in Monitoring the lonosphere in Brazil During Quiet and Disturbed Days. Bulletin of Geodetic Sciences, 25(spe): e2019s005, 2019. 


\section{Introduction}

The atmosphere has great influence on the propagation of Global Navigation Satellite System (GNSS) signals, thus impelling numerous activities related to positioning from space observations and research related to the behavior of the ionosphere. GNSS measurements have become an important source of data for these studies. Various information sources are used in the development of ionospheric models, offering different applications, such as GNSS positioning (Macalalad et a., 2016), the study of ionospheric morphology and dynamics (Lin et al., 2005; Biqiang et al., 2007), and ionospheric monitoring (Linty et al., 2015; McCafferey et al., 2018).

Total electron content (TEC) is one of the most important parameters used to describe the proprieties of the ionosphere. Ionospheric models use the dispersive propriety of the ionosphere on GNSS with the aim of describing TEC in space and time. Variations in electron density cause ionospheric scintillations which lead to fluctuations in carrier-wave amplitude and phase. A weakening of received power may cause loss of lock (Leick, 1995; Conker et al., 2003).

It is possible to carry out studies of ionospheric behavior using GNSS networks. From these data, TEC can be estimated and, consequently, its rate of change of TEC, and thus the irregularity indices: $f_{p}, F_{p} I_{R O T}$ and ROTI (Mendillo et al., 2000; Pi et al., 1997; Wanninger, 1993). Another widely used tool is the all-sky imager, used to measure the intensity of an emission, providing absolute measurements of atmospheric nocturnal luminescence (nightglow) to obtain information about the ionospheric layer (Pimenta et al. 2003; Wrasse et al., 2007; Martinis et al., 2018). Furthermore, it is also possible to conduct studies of the behavior of the ionosphere by ionosondes which provide the electron density profile, a device that works by the emission of vertical electromagnetic energy pulses in relation to the ground (Yamashita, 1999). One of the advantages of ionosondes and GNSS networks compared to optical equipment, which is hampered by clouds and sunlight, is their ability to operate uninterruptedly, producing long time series of data.

The ionosphere varies according to magnetic activity, season, solar cycles and geographic location, being more intense in the equatorial regions (where a large part of the Brazilian territory is located). Brazil is therefore in a special region for carrying out studies of ionospheric behavior. The ionospheric layer over the Brazilian territory has consequently been studied by several researchers (Chu et al., 2005, Muella et al., 2008, Abreu et al., 2014, Pereira and Camargo, 2017).

The aim of this work is to perform an analysis of ionospheric behavior in the Brazilian region during quiet and disturbed days, using ionospheric irregularity indices along with ionospheric and imager information with the purpose of evaluating the performance of each technique presented. The integration of these forms of ionospheric layer monitoring becomes of great relevance as these monitoring methods provide a range of information about ionospheric behavior. The information can assist in the production of prediction models which are of great importance when it comes to GNSS positioning.

\section{Methods of Analysis}

The irregularity indices have the main function of classifying the state of the ionosphere, according to a standard established from GNSS information. The estimates of these indices are based on the rate of change of TEC, the ROT. Several indices can be used for the classification and investigation of ionospheric behavior, for example, irregularity indices such as $\mathrm{fp}$ and $\mathrm{F}_{\mathrm{p}}$ (Mendillo et al., 2000), 
$I_{\text {ROT }}$ (Wanninger, 1993) and ROTI (Pi et al., 1997). The Fp index is based on the fp index, which is obtained by the median of the ROTs eliminating possible high values; the $I_{\text {ROT }}$ index is obtained by the RMS (Root Mean Square), and ROTI this is acquired from the standard deviation.

The ionosonde is an instrument that measures the electron density profile of the ionosphere through the emission of pulses (echoes) of vertical electromagnetic energy in relation to the ground. These echoes are recorded by the ionosondes and organized according to the frequency of transmission and the height of reflection of the electromagnetic pulses to form the so-called ionograms (Yamashita, 1999). A range of ionospheric parameters can be extracted from ionogram analysis. Table 1 shows the parameters provided by an ionosonde. Usually, the ionospheric parameters are divided into specific groups. The parameter containing the letter $E$ in its name is specific to the layer E; the group of parameters specific to the layer F, include F1 or F2 in their names; a last group, containing neither of the letters $E$ and $F$, provide information independent of ionospheric layers.

Table 1: Ionospheric parameters extracted from the ionogram and their respective descriptions

\begin{tabular}{l|l}
\hline Parameter & Description \\
\hline fmin & Lower frequency at which the echo trace was observed \\
\hline fbEs & $\begin{array}{l}\text { Lower frequency of the ordinary wave, in which the continuous trace of the } \\
\text { sporadic layer was observed }\end{array}$ \\
\hline$h^{\prime} E s$ & $\begin{array}{l}\text { Maximum frequency of the ordinary wave, in which the continuous trace of the } \\
\text { sporadic layer was observed }\end{array}$ \\
\hline TIPO & Minimum virtual height of sporadic layer observed \\
\hline foE & $\begin{array}{l}\text { Corresponds to type (s) of sporadic layer observed } \\
\text { of the E region which causes discontinuity at the height of trace } E\end{array}$ \\
\hline MUF & Maximum Usable Frequency \\
\hline$h^{\prime} E$ & Minimum virtual height of layer $E$ \\
\hline foE2 & $\begin{array}{l}\text { Critical frequency of the ordinary wave of the E2 layer, which sometimes } \\
\text { appears between the normal E layer and the F1 layer }\end{array}$ \\
\hline$h^{\prime} E 2$ & Minimum virtual height of layer E2 \\
\hline foF1 & Critical frequency of the ordinary wave of layer F1 \\
\hline foF2 & Critical frequency of the ordinary wave of the highest layer of the F region \\
\hline$h^{\prime} F$ & Minimum virtual height of layer $F$ \\
\hline$h^{\prime} F 2$ & Minimum virtual height of ordinary trait \\
\hline hmF2 & Peak height of electronic density of layer F2 \\
\hline $\mathrm{NmF2}$ & Density of Electrons present in Layer F2 \\
\hline
\end{tabular}

Source: Yamashita, 1999.

Ionospheric irregularities manifest in the ionograms as a degradation of the signal, or a scattering when compared to the echo that would be detected in default of them (Yamashita, 1999). Figure 1 presents two ionograms generated for the Boa Vista (RR) station, in (a) 1 February 2015, the irregularities are presented as a scattering (degradation) of the echoes and in (b)1 May 2015, the absence of irregularities. 

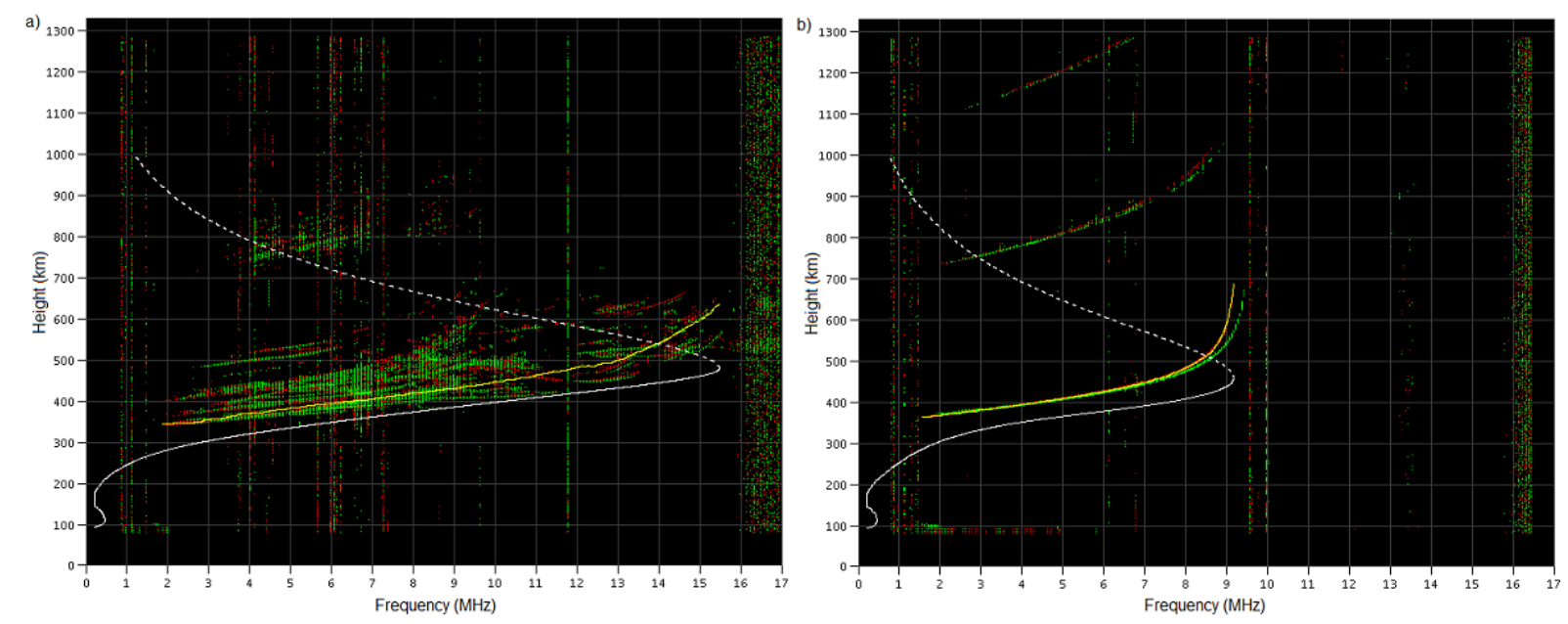

Figure 1: lonograms for the BOAV/RR station (a) February 1st, 2015, the echoes shown in this ionogram are scattered in the vertical or altitude direction; (b) May1st, 2015, an ionogram without spreading is shown, in other words, without ionospheric irregularities manifestation

Imagers are considered an evolution of photometers which were one of the first instruments whose goal was the capture of atmospheric luminescence. Images of different emissions of luminescence make it possible to improve studies of the morphology and dynamics of the ionosphere at different altitudes. Using images from all-sky imagers, it is possible to identify the ionospheric bubbles through dark structures that are regions where the plasma density is reduced in relation to the ambient plasma. Figure 2 illustrates the plasma bubbles occurring over the field of view of the imagers, through the emission Ol $630.0 \mathrm{~nm}$ for São Joao do Cariri (PB), 1 March 2013.

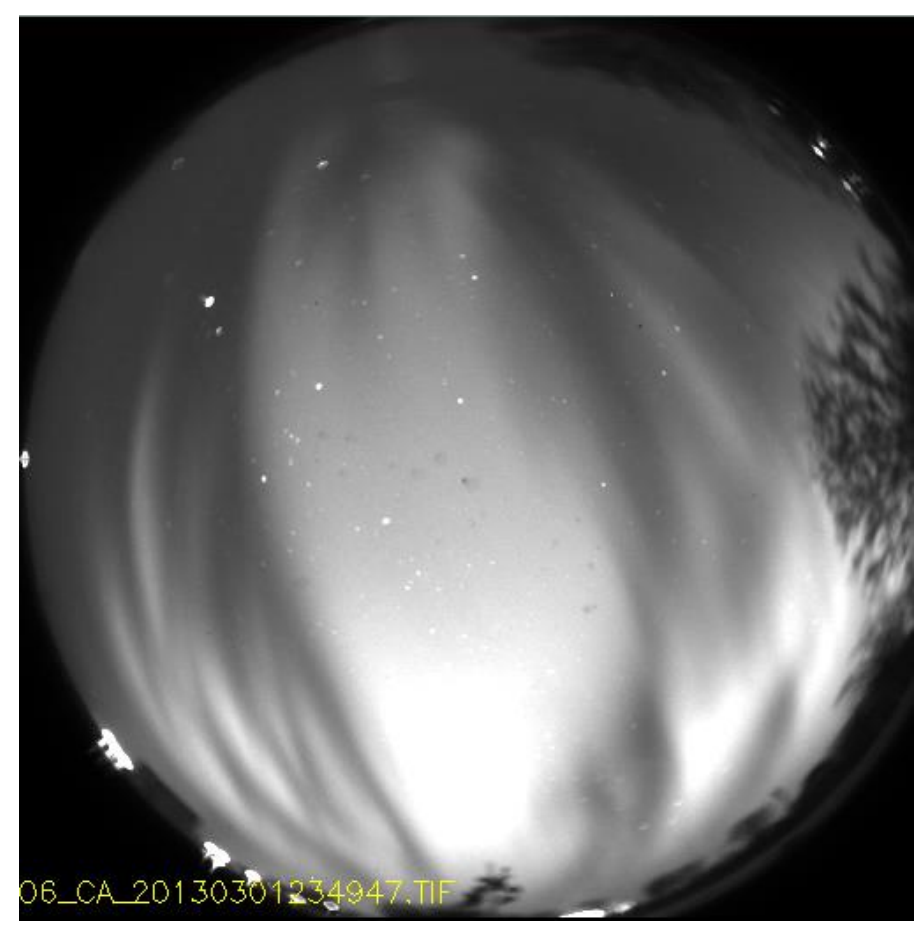

Figure 2: Image obtained through the emission Ol 630.0 nm, in São João do Cariri - PB, March 1st, 2013, showing the plasma bubbles occurrence 


\section{Methodology}

In this work, information of the ionospheric irregularity indices was compared and correlated, together with information concerning ionospheric parameters derived from ionosondes and data of the optical imagers. The ionospheric irregularity indices were estimated for the BOAV station located in Boa Vista (RR), belonging to the Brazilian Network for Continuous GNSS Monitoring (RBMC), using lon_Index software (Pereira and Camargo, 2016). The BOAV station was chosen due to its geographic location, close to the geomagnetic equator, because it is characterized by large ionospheric impacts. In addition, the region of the BOAV station also presents information from imagers as well as ionosondes.

The date of 1 March 2014 was selected because it is characterized by strong irregularities due to an increase in the electron density variation near the Southern autumnal equinox. The year is significant because it corresponds to the apex of solar cycle 24. The ionospheric parameters h'F (minimum virtual height of trace F), hmF2 (peak height of electronic density of layer F2) and NmF2 (maximum density of electron of layer F2) were also obtained from the ionosondes for the same location and day, as well as images obtained from all-sky imagers located in Boa Vista/RR. lonosphere and imager information is provided by the Brazilian Studies and Monitoring of Space Weather (EMBRACE) program, on the National Institute for Space Research (INPE) website.

The same comparison was repeated for a day of low solar activity, 12 April, 2015. Irregularity indices were again estimated, along with the ionospheric parameters obtained through the ionosondes and information from the optical imagers.

Figure 3 shows the geographic location of nocturnal luminescence (nightglow) instruments used for the monitoring of the ionospheric layer in the present work. The GNSS stations belonging to RBMC are represented in red. The network currently has 151 stations, where data is collected every 15 seconds and made available every 24 hours by the the Brazilian Institute of Geography and Statistics (IBGE). The all-sky imagers are represented in blue. There are only 4 in Brazilian territory, one of which is currently inactive. The imager data are collected at night in favorable weather conditions and are made available by INPE. The ionosondes are represented in green. INPE has 7 ionosondes, of which two are inactive. The data are collected every 10 minutes and made available by INPE.

It is important to note that both GNSS networks and ionosondes collect data every 24 hours which are later made available by the responsible agency, producing a considerable body of data. However, the same does not apply to the imagers which only collect data at night, when atmospheric luminescence is necessary to capture the images. Furthermore, the presence of cloud or haze impedes the collection of night images. 


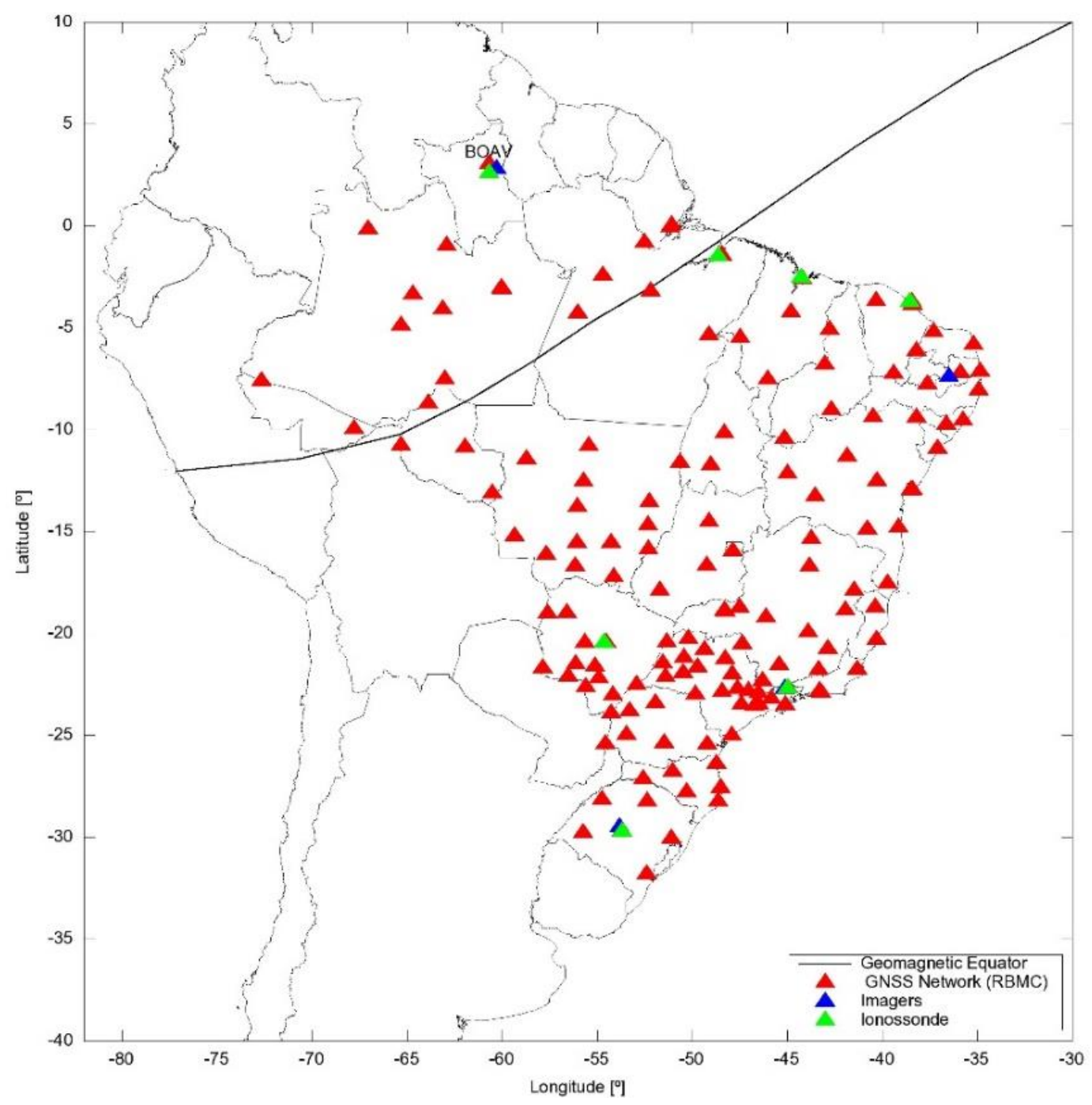

Figure 3: Geographic location of the instruments

\section{Results and Discussion}

Figures 4 and 5 respectively show the $\mathrm{fp}, \mathrm{FP}_{\mathrm{p}} \mathrm{I}_{\mathrm{ROT}}$ and ROTI indices, and the BOAV station ionosonde parameters. A $35^{\circ}$ elevation mask and an altitude of $350 \mathrm{~km}$ was considered. In Figure 2 the green line indicates the border between low and moderate levels of ionospheric irregularities, while the red line indicates the limit between moderate and strong levels, according to Mendillo et al., 2000 and Pereira and Camargo, 2013 

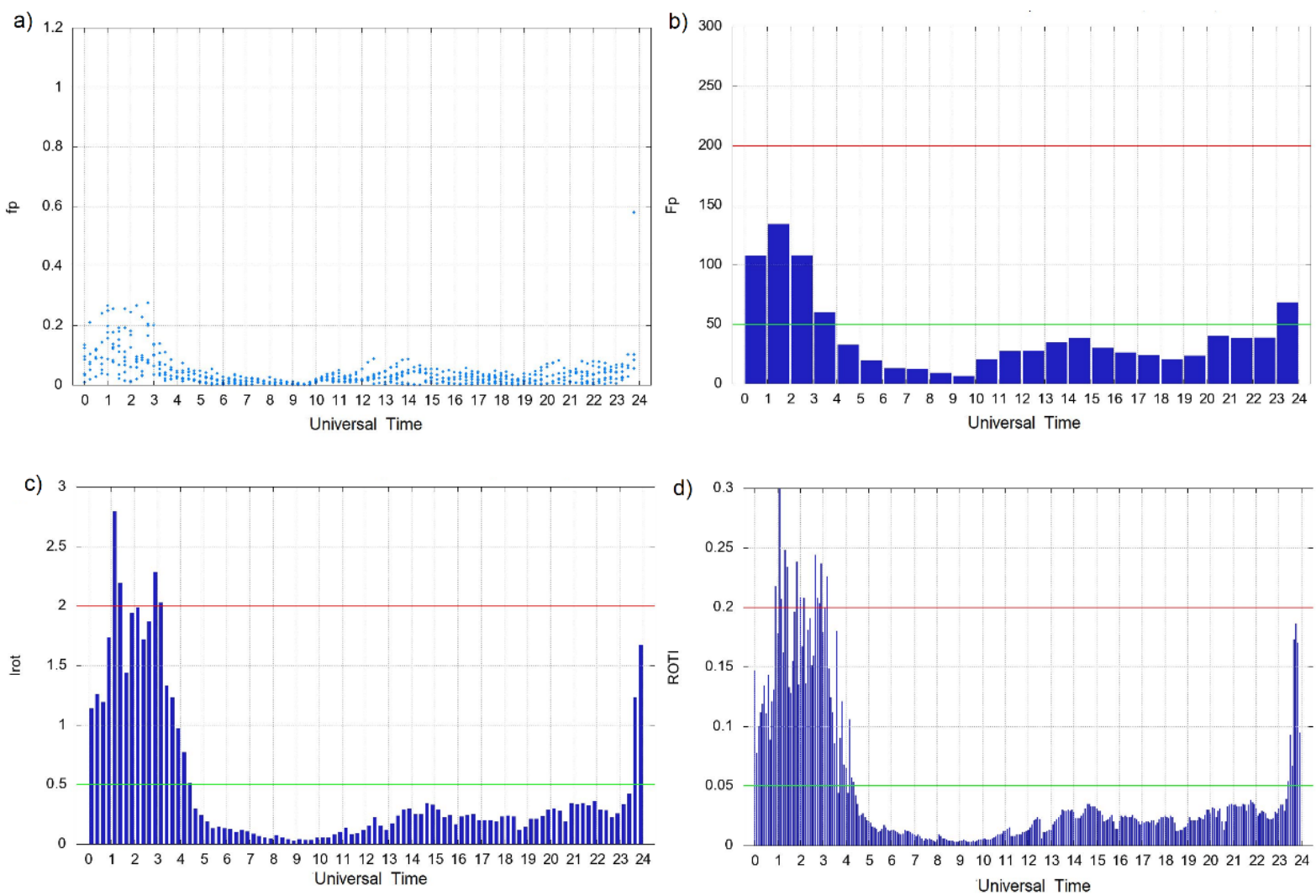

Figure 4: Irregularity indices for the BOAV/RBMC station, March 1st, 2014. a) fp; b) Fp; c) IROT; d) ROTI.
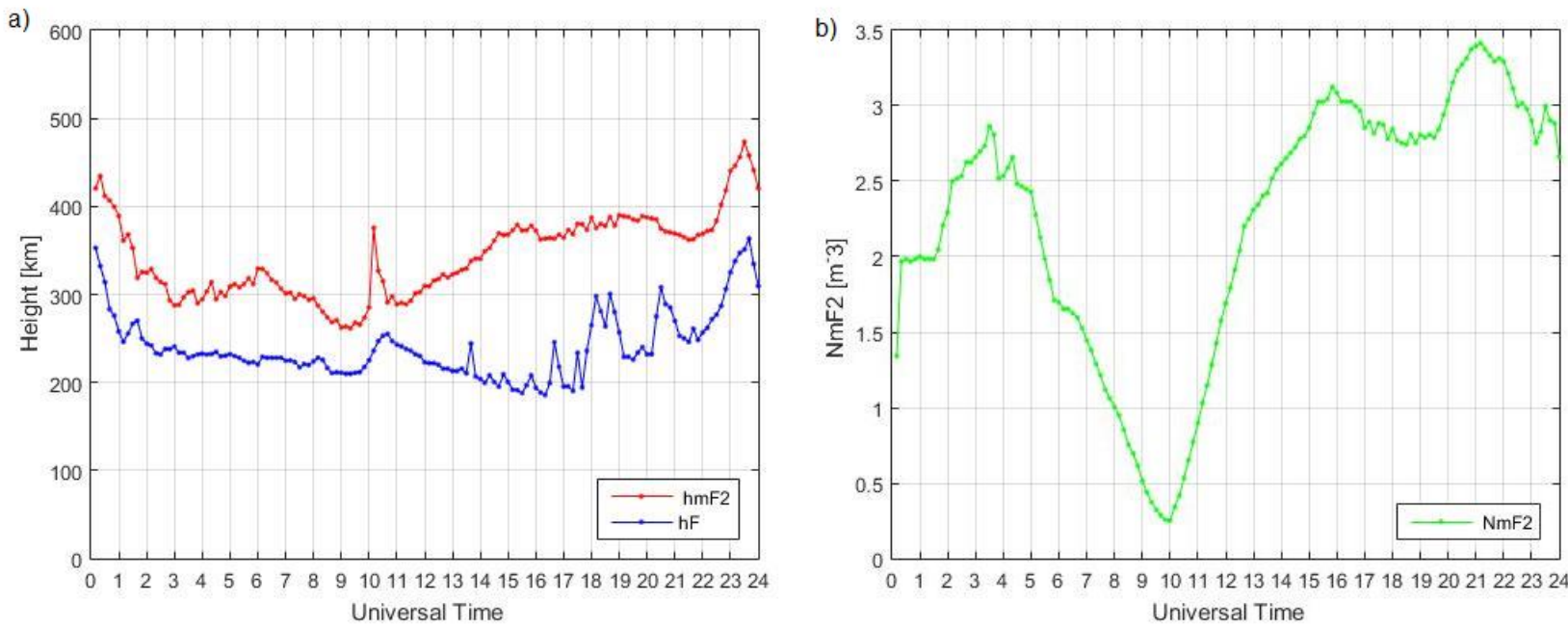

Figure 5: lonosonde Parameters for the BOAV/RBMC station, March 1st, 2014. a) hmF2 and h'F;

b) NmF2;

When analyzing the irregularity indices (Figure 4), it was observed that values remained below the classification thresholds of low levels of ionospheric irregularity (green line) during the day, except for the 00-04h UT and 23-24 h UT period, with the level of the same reaching an Fp value of 140, IROT above 2 and ROTI higher than 0.2 . 
In addition, considering the $F_{p}$ index, the irregularities are classified as moderate, whereas the IROT and ROTI values indicate strong irregularities. This is justified by the data periods and the way in which the indices are calculated: ROTI and IROT indices consider all ROT values obtained, thus providing higher values than $\mathrm{F}_{\mathrm{p}}$. It can therefore be said that the IROT and ROTI indices detail ionospheric irregularities better than the $\mathrm{Fp}$ index, because both are obtained from smaller data periods than the $\mathrm{Fp}_{\mathrm{p}}$ index. For the $\mathrm{I}_{\mathrm{ROT}}$ index, the period is 15 minutes, for ROTI it is 5 minutes and for $F_{p}$ it is 1 hour. Hence the $I_{\text {ROT }}$ and ROTI indices identify small-scale signal fluctuations, while the $F_{p}$ index depicts the overall level of irregularities.

Analyzing the ionosonde parameters (Figure 5) during the 00-04h UT period, the values of parameters h'F and hmF2 were high, thus proving the duration and level of the irregularity presented by the indices. The parameter h'F presented an average value of $240 \mathrm{~km}$, with a maximum of $370 \mathrm{~km}$. The height of the ionization peak was an average of $345 \mathrm{~km}$, with a maximum of $475 \mathrm{~km}$. The maximum electron density of the F2 layer (NmF2) confirms the behavior of the ionosphere irregularity indices. During 00-04h AM UT there was a rise in electronic density, obtaining a maximum of $2.8 \mathrm{~m}^{-3}$, and also in the $23-24 \mathrm{~h}$ UT, where the density reached $3.4 \mathrm{~m}^{-3}$, after a decline.

Pearson correlation coefficients were calculated between the irregularity index $\mathrm{Fp}_{\mathrm{p}}$ and the ionospheric parameters for the period of high variability of electron density. The correlation values were modest: $0.40,0.44$, and 0.70, between the Fp index and parameters $h ' F, h m F 2, N m F 2$ respectively. In addition, scatterplot was made between the ionospheric indices ( $F_{P}, I_{R O T}$ and ROTI) and the electronic density of the F2 layer parameter, shown in the Figure 6 . It is important to note that the choice of the Fp index to calculate the correlations was due to its ability to describe the ionospheric irregularities at a more general level.
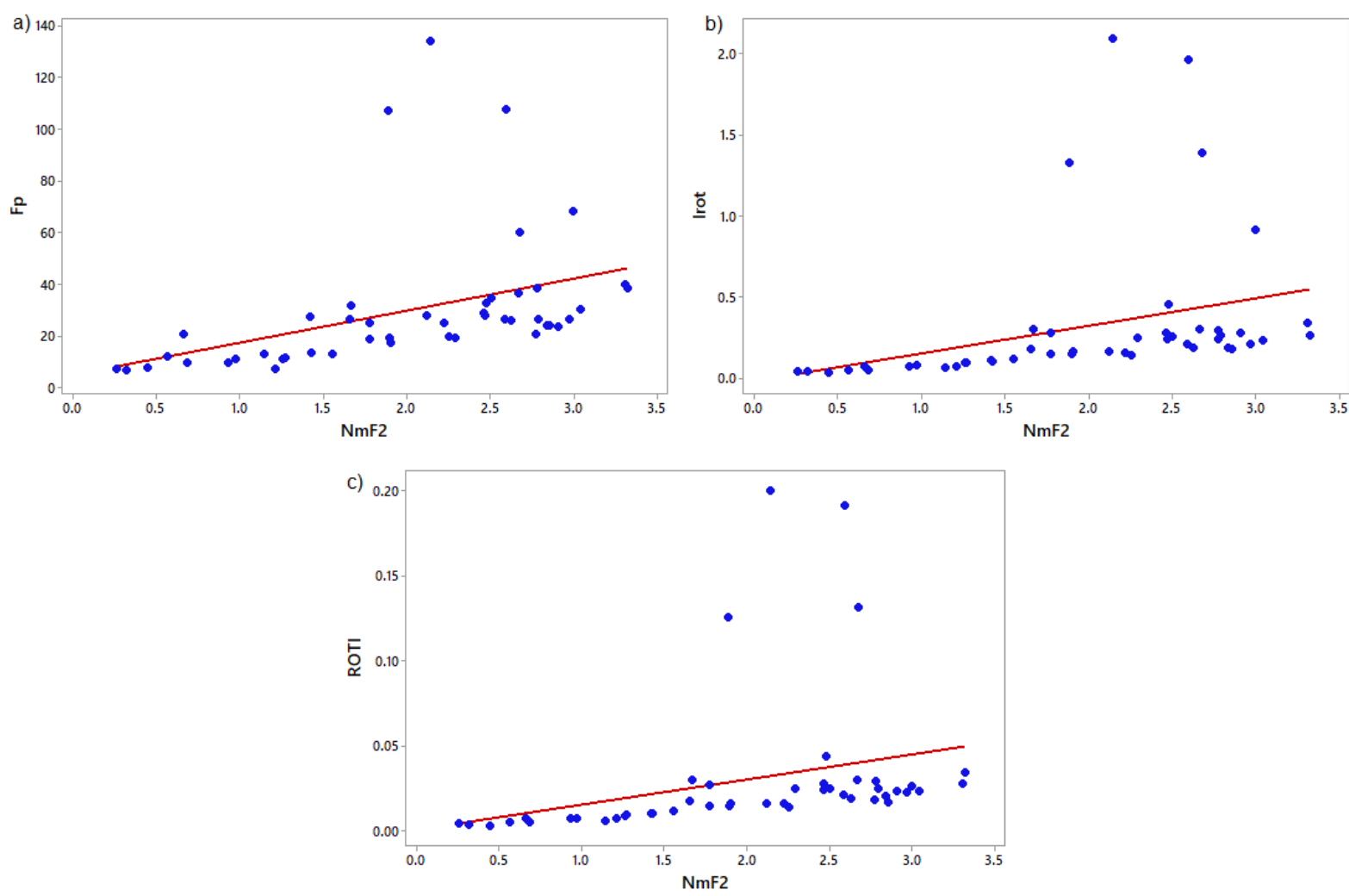

Figure 6: Scatterplot between ionospheric irregularity indices and the ionosonde parameters (NmF2). a) Fp; b) IROT; c) ROTI; 
Analyzing scatterplot between ionospheric irregularity indices and ionosonde parameter, electronic density of the F2 layer (Figure 6), it was observed that all irregularity indices showed a moderate and positive correlation. Excluding the outliers present in scatterplot, the correlation between and the ionosonde parameter $\mathrm{NmF2}$ and ionospheric irregularity indices $\mathrm{Fp}$, IROT ROTI becomes $0.75,0.65,0.81$ respectively, indicating strong and positive correlation.

The estimated irregularity indices of the instant 01:00 UT 1 March, 2014, presented the highest values. The respective ionogram was obtained (Figure 7), from which the irregularities can be verified by scattering (degradation) of the echoes. The traces are not well defined on the ionogram, scattered in altitude direction.

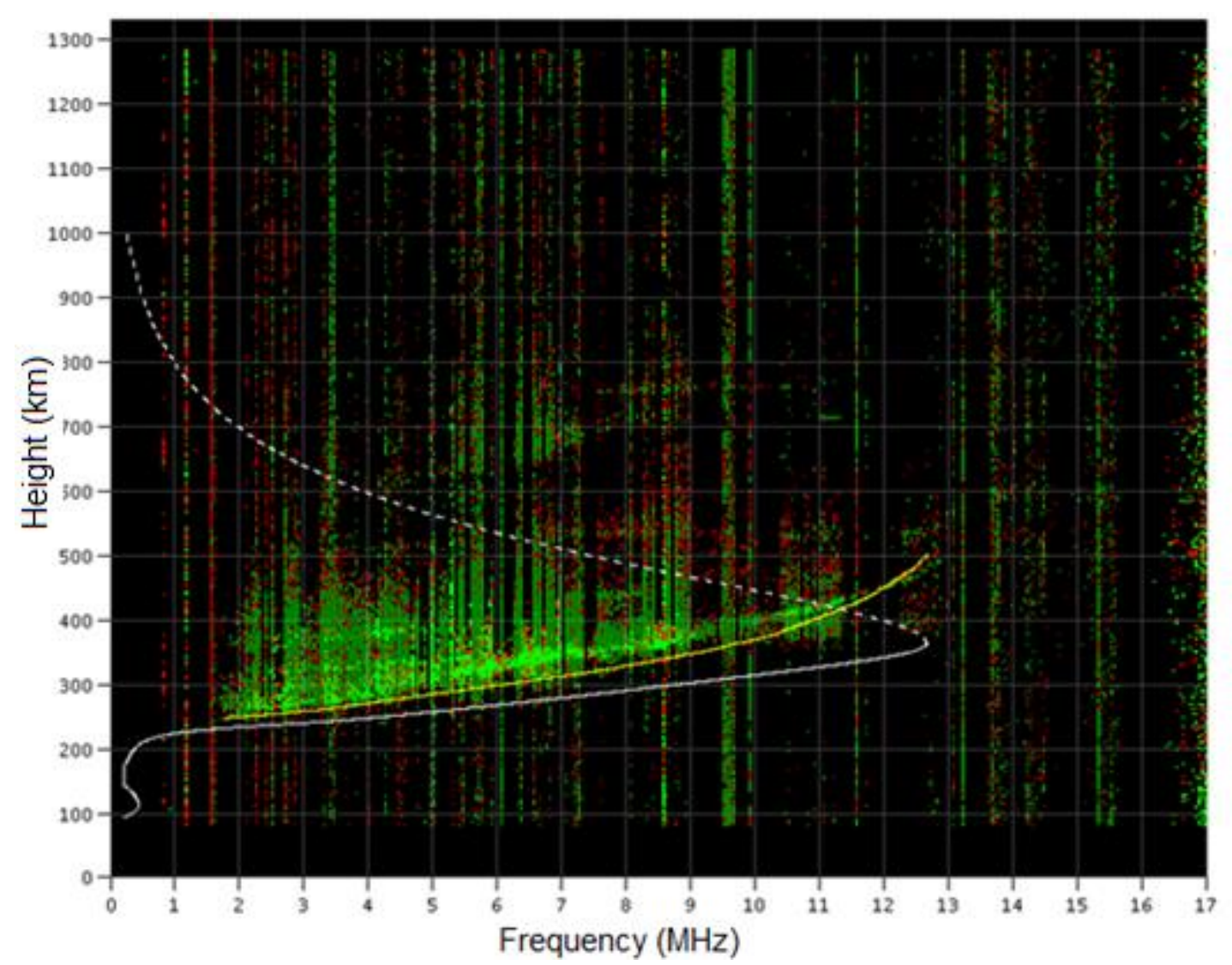

Figure 7: lonogram for the BOAV/INPE station, instant 01:00 UT, 1 March, 2014.

The images with all-sky optical imagers were also obtained for the range of the largest irregularities (00-04h UT). These irregularities were able to generate ionospheric bubbles (Figure 8), which are often capable of causing fluctuations in the GNSS signals (ionospheric scintillation). These periods are associated with the existence of small-scale irregularities in electron density. 




Figure 8: All-sky images from the BOAV/INPE station, 00 - 04 UT, 1 March, 2014.

In order to check results, the same tests were also carried out for a day of low solar activity, 12 April, 2015 being the day selected. Figures 9 and 10 show the ionospheric irregularity indices and the ionospheric parameters from the ionosondes, again for the BOAV station. 

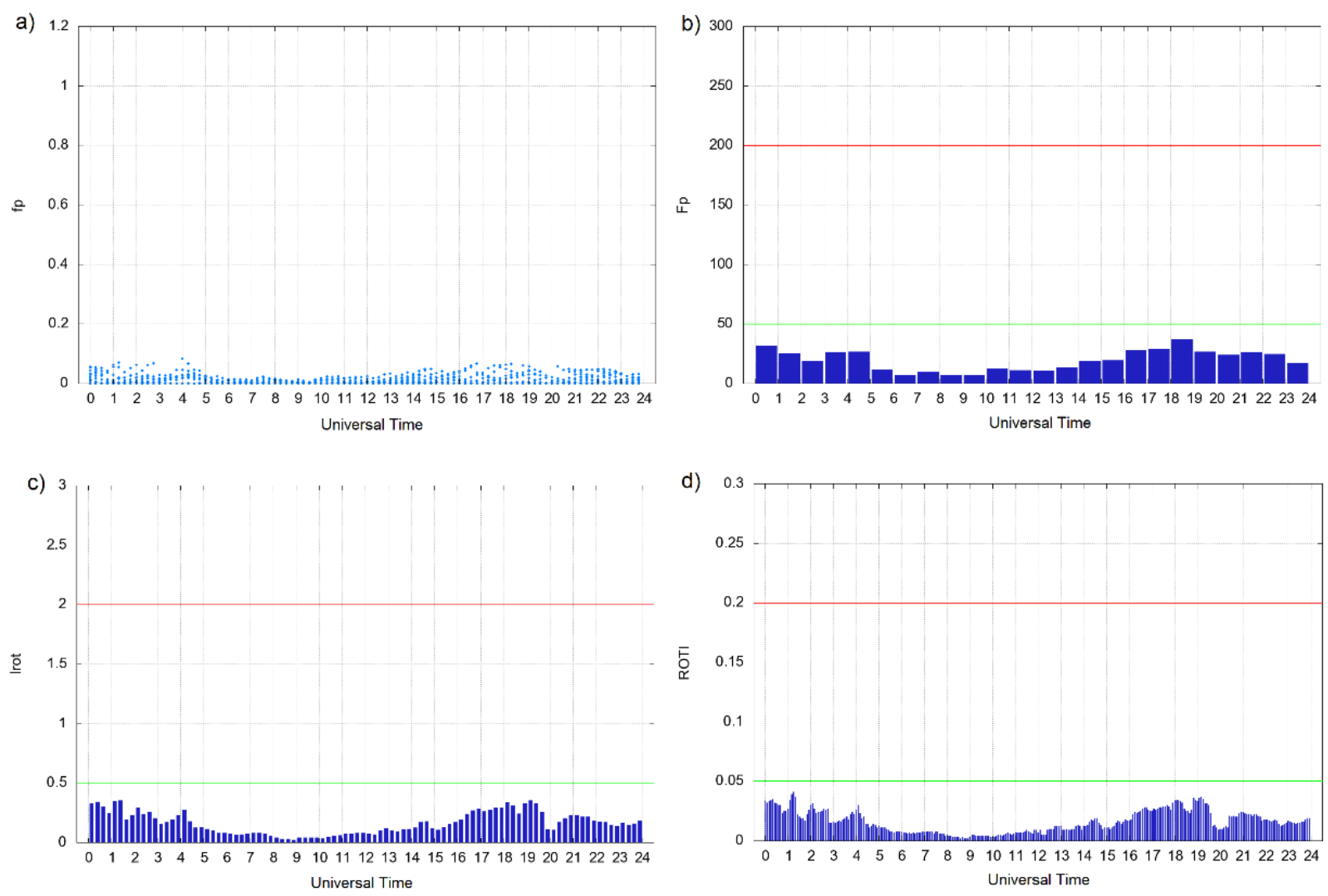

Figure 9: Irregularity indices for the BOAV/RBMC station, April 12, 2015. a) fp; b) Fp; c) IROT; d) ROTI.
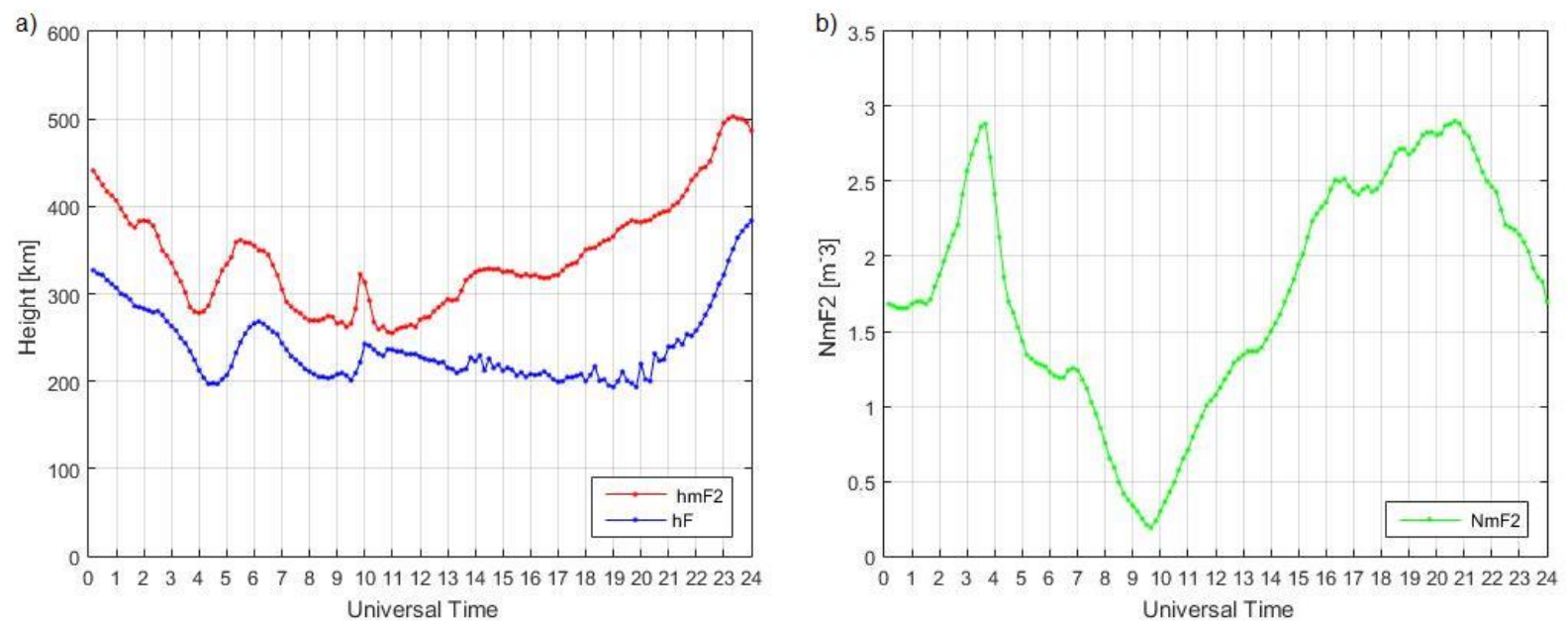

Figure 10: Ionosonde Parameters for the BOAV/RBMC station, April 12, 2015. a) hmF2 and h'F;

b) NmF2;

Analyzing the irregularity indices (Figure 9), it was observed that the values remained below the classification thresholds of low levels of irregularities of the ionosphere (green line) throughout the day. It can therefore be inferred that the ionosphere was calm, as expected, as the selected day corresponds to a period of low ionospheric activity. It can nevertheless be seen that, in the period from 00-04h UT, and at around 18-22h UT, there was a small variation in the electron 
irregularities present in the ionospheric layer, but this was insufficient to raise the indices, classifying the selected day as a calm day.

Considering the ionospheric parameters from the ionosondes (Figure 10), it can be seen that the parameter h'F presented an average value of $239 \mathrm{~km}$, with a maximum of $383 \mathrm{~km}$, and the height of the ionization peak is an average of $342 \mathrm{~km}$, with a maximum of $503 \mathrm{~km}$. The maximum electron density of the F2 layer ( $\mathrm{NmF2}$ ) confirms the behavior of the ionosphere irregularity indices. During 00-04 $\mathrm{h}$ UT there was a rise in the electron density, obtaining a maximum of $2.8 \mathrm{~m}^{-3}$, as well as in the 18-22 h UT, where the density reached $2.00 \mathrm{~m}^{-3}$. It can be seen from the ionospheric parameters from the ionosondes $\mathrm{h}^{\prime} \mathrm{F}$ and $\mathrm{hmF} 2$ that the indices presented similar values. However this behavior was not expected as the days selected have different characteristics. However, when analyzing the ionospheric parameters of 1 March 2014, the values presented the greatest variations when compared to 12 April 2015. This behavior can be evidenced between $18.00 \mathrm{~h}$ and 20.00 h UT.

When considering the instant 18:00 UT of 12 April 2015, the estimated irregularity indices of which presented the highest values, the relevant ionogram was obtained (Figure 11). It can be seen that there were no ionospheric irregularities as the traces of the ionogram were well defined.

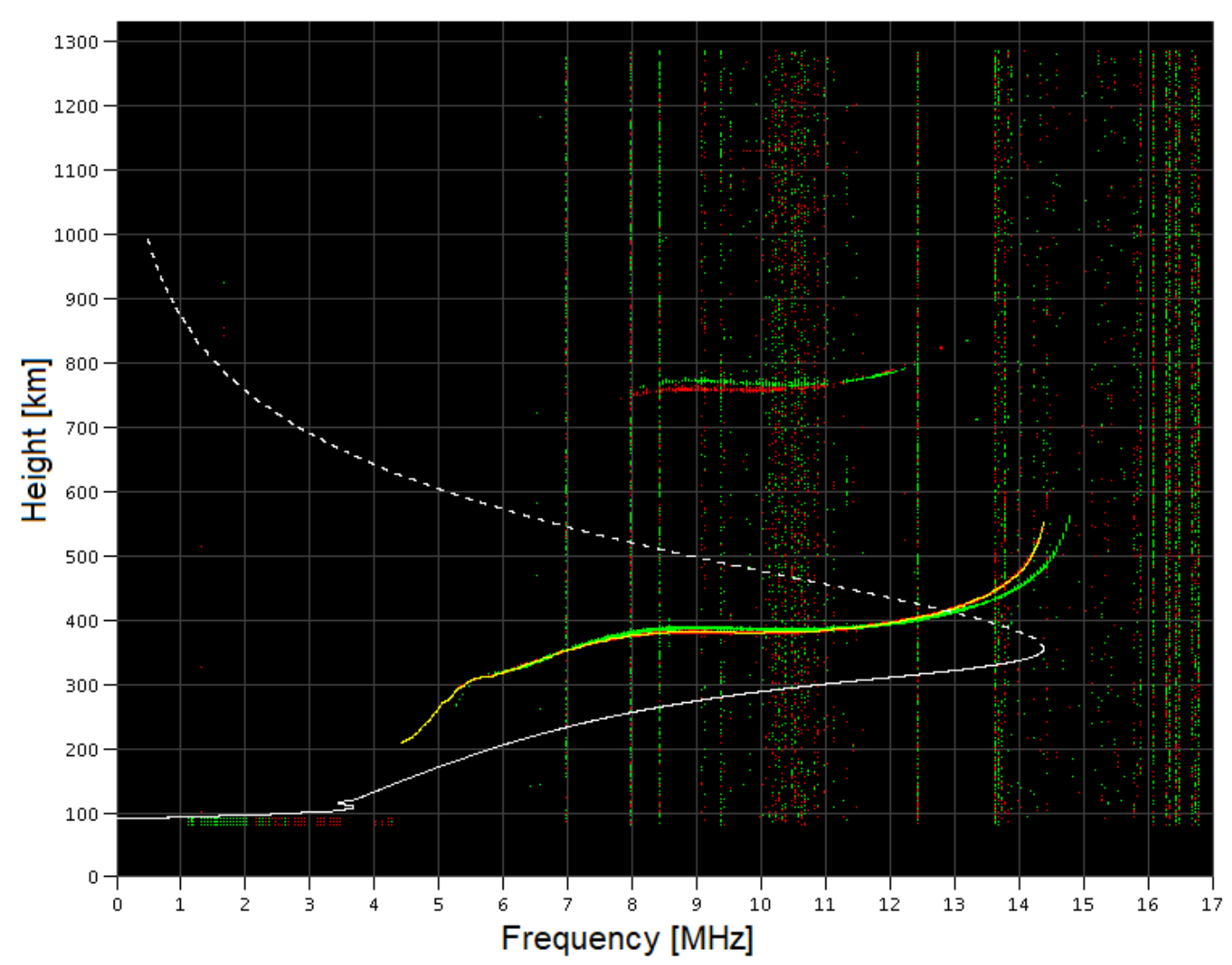

Figure 11: lonogram for the BOAV/INPE station, instant 18:00 UT, April 12, 2015.

Images from optical imagers were obtained for one of the periods in which there were the largest ionospheric irregularities (00-04 h UT) (Figure 12). It can be verified that the ionospheric irregularities present were not able to generate ionospheric bubbles. Although the images are impaired by the meteorological conditions, it is possible to see that there were no bubbles, as was expected. 


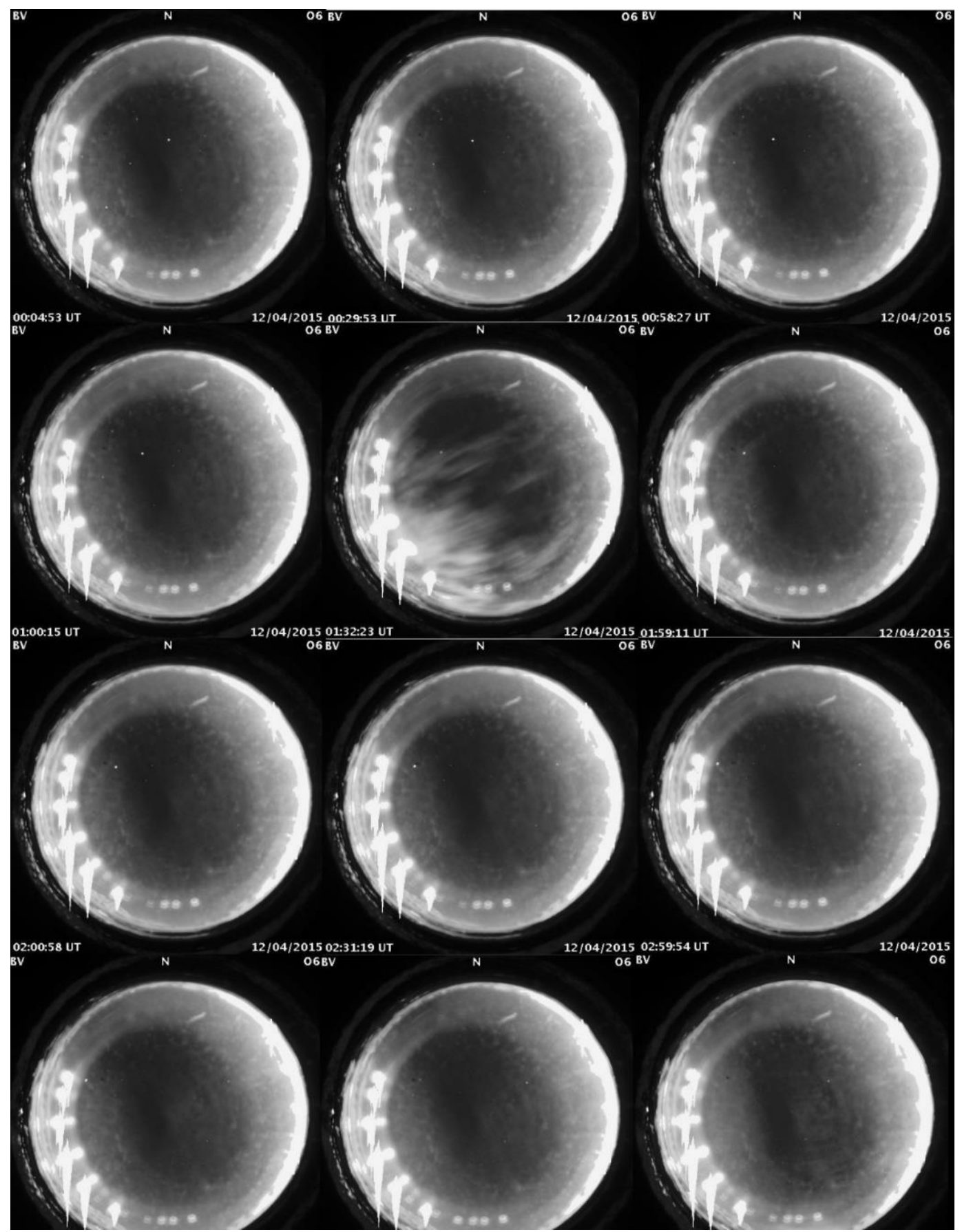

Figure 12: All-sky images for the BOAV/INPE station, 00 - 04 UT, April 12, 2015.

It has been observed that each technique for monitoring the ionospheric layer presents its advantages and disadvantages. The imagers enable measures of greater spatial extent to be carried out, as compared to the ionosonde, enabling the observation of extensive areas. However, for imagers to be used to maximum effect, it is necessary to have favorable weather conditions without mist or clouds.

Ionosondes are equipped with a higher capacity for diagnosis of the ionosphere and can operate continuously for long periods producing long time series, allowing inferences to be made about 
the ionosphere's behavior as well as the weather in space. However, these devices, like optical imagers, exist only in small numbers in Brazilian territory.

The growth of GNSS technology in recent years has led to it being used as an alternative way of studying the ionosphere. Combining the dispersive property of the ionospheric layer with GNSS signals in multiple carrier frequencies makes it possible to estimate TEC, which is the main parameter capable of describing the behavior of the ionosphere. And with the implementation of active network stations, GNSS signal monitor stations are becoming ionosphere layer monitoring stations capable of estimating ionospheric irregularity rates. This densification of stations enables an improvement in spatial resolution, as the number of instruments dedicated to the monitoring of the ionosphere in Brazil is reduced, thus enabling a better understanding of ionospheric phenomena throughout Brazilian territory.

Integration of the forms of ionospheric layer monitoring has become of great relevance, as it provides a great deal of information about the behavior of the ionosphere. Such information can contribute to the development of prediction models, which are of great importance when it comes to real-time positioning, one of the major trends in the current era.

\section{Conclusions}

Different technologies were analyzed for the monitoring of the ionospheric layer. It has become essential to correlate these forms of monitoring, presenting their advantages and disadvantages. With this in mind, the aim of this work was to perform an analysis of the behavior of the ionosphere in the Brazilian region through the ionospheric irregularity indices, along with ionosonde information and all-sky optical imagers.

Two different scenarios were chosen for the experiments carried out in the work. For the first experiment, 1 March 2014 was considered, as it is characterized by the presence of a high variability in the density of electrons in the ionosphere. The second was 12 April 2015, characterized by low levels of ionospheric irregularities. The results for each monitoring technique were compatible. The results showed a positive and moderate correlation between the $\mathrm{Fp}_{\mathrm{p}}$ irregularity index and the ionospheric parameters, being approximately $0.70 ; 0.40 ; 0.44$ with the parameters NmF2, h'F and hmF2, respectively, allowing an evaluation of the behavior of the ionosphere and the climate, through irregularity indices, ionosonde parameters, and imagers.

Regarding the irregularity indices investigated, it is concluded that ROTI index should be used for the temporal study of ionospheric irregularities while spatial study should be performed by the $\mathrm{f}_{\mathrm{p}}$ index. The $\mathrm{Fp}_{\mathrm{p}}$ index is used for general purposes, this is when a value representing the general level of ionospheric irregularities is required.

It can be seen that each technique for monitoring the ionospheric layer presents its advantages and disadvantages. There is only a limited number of imagers and ionosondes distributed throughout the Brazilian territory, with insufficient data for the monitoring and more detailed analysis of ionospheric irregularities.

The use of GNSS network stations therefore becomes an convenient way of monitoring the ionospheric layer, as they provide a greater set of information about the Brazilian ionosphere, which in return serves to feed mitigation models, as well as increasing the level of spatial resolution, as the number of instruments dedicated to the monitoring of the ionosphere in Brazil 
is reduced. This densification allows a better understanding of the dynamics of the main ionospheric effects in Brazil.

\section{ACKNOWLEDGEMENT}

The authors would like to acknowledge the Conselho Nacional de Desenvolvimento Científico e Tecnológico (CNPq) for supporting this research (processes 479965/2013-7 and 309924/2013-8). We also would like to thank INPE for providing ionosonde and imager data.

\section{AUTHOR'S CONTRIBUTION}

Both authors contribute equally.

\section{References}

Abreu, A. J., Fagundes, P. R., Bolzan, M. J. A.; Gende, M.; Brunini, C.; De Jesus, R.; Lima, W. L. C. 2014. Traveling planetary wave ionospheric disturbances and their role in the generation of equatorial spread-F and GPS phase fluctuations during the last extreme low solar activity and comparison with high solar activity. Journal of Atmospheric and Solar-Terrestrial Physics, v. 117, pp. 7-19.

Biqiang, Z.; Weixing, W., Libo, L.; Tian, M. 2007. Morphology in the total electron content under geomagnetic disturbed conditions: results from global ionosphere maps. Annales Geophys, pp. 1555-156.

Chu, F. D.; Liu, J. Y.; Takahashi, H.; Sobral, J. H. A.; TAYLOR M. J.; Medeiros A.F. 2005. The climatology of ionospheric plasma bubbles and irregularities over Brazil. Annales Geophysica, European Geosciences Union, pp. 379-384.

Conker; R. S., El-arini, M. B. Hegarty, C. J., Hsiao, T. 2003. Modeling the Effects of Ionospheric Scintillation on GPS/Satellite-Based Augmentation System Availability, Radio Science, v. 38.

Leick, A. 1995. GPS satellite surveying. 2. ed. New York: John Wiley \& Sons, 560 p.

Lin, C. H.; Richomound, A. D. Liu, J. Y.; Yeh, H. C.; Paxton, L. J.; Lu, G.; Su, S. Y. 2005.Large-scale variations of the low-latitude ionosphere during the October-November 2003 superstorm: Observational results. Journal of Geophysical Research: Space Physics, v. 110.

Linty, N.; Romero, R.; Dovis, F.; Alfonsi, L. 2015. Benefits of GNSS software receivers for ionospheric monitoring at high latitudes. 1st URSI Atlantic Radio Science Conference (URSI ATRASC). IEEE, pp. 1-6.

Macalalad, E. P.; Tsai, L. C.; Wu, J. 2016. Performance evaluation of different ionospheric models in single-frequency code-based differential GPS positioning. GPS solutions, v. 20, n. 2, pp. 173-185.

Martinis, C.; Baumgardner, J.; Wroten, J.; \& Mendillo, M. 2018. All-sky-imaging capabilities for ionospheric space weather research using geomagnetic conjugate point observing sites. Advances in Space Research, v. 61, n. 7, pp. 1636-1651.

McCaffrey, A. M.; Jayachandran, P. T.; Langley, R. B.; Sleewaegen, J. M. 2018. On the accuracy of the GPS L2 observable for ionospheric monitoring. GPS Solutions, v. 22, n. 1, pp. 23. 
Mendillo, M.; Lin, B.; Aarons, J. 2000. The application of GPS observations to equatorial aeronomy. Radio Science. v. 35 (3), pp. 885-904.

Muella, M. T. A. H.; De Paula, E. R.; Kantor, I. J.; Batista, I. S.; Sobral, J. H. 2008. Scintillations and ionospheric irregularity zonal grifts inferred at equatorial and low-latitude regions, Journal of Atmospheric and Solar Terrestrial Physics, pp. 1261-1272.

Pereira, V. A. S.; Camargo, P. O. 2013. Estimativa e análise de índices de irregularidades da ionosfera utilizando dados GPS de redes ativas. Boletim de Ciências Geodésicas, v. 19, n. 3. pp. 374-390.

Pereira, V. A. S.; Camargo, P. O. 2016. Programa científico para o monitoramento em tempo real ou pós-processado das irregularidades ionosféricas e cintilação dos sinais GNSS. Boletim de Ciências Geodésicas, v. 22 (2), pp. 282-302.

Pereira, V. A. S.; Camargo, P. O. 2017. Brazilian active GNSS networks as systems for monitoring the ionosphere. GPS Solutions, v. 21, n. 3, pp. 1013-1025.

Pi, X.; Mannucci, A. J.; Lindqwister, U. J.; Ho, C. M. 1997. Monitoring of global ionospheric irregularities using the worldwide GPS network. Geophysical Research Letters, v. 24, n. 18, pp. 2283-2286.

Pimenta, A. A.; Bittencourt, J. A.; Fagundes, P. R.; Sahai, Y.; Buriti, R. A.; Takahashi, H.; Taylor, M. J. 12003. Ionospheric plasma bubble zonal drifts over the tropical region: a study using Ol 630nm emission all-sky images. Journal of Atmospheric and Solar-Terrestrial Physics, v. 65, n. 10, p. 11171126.

Wanninger, L. Ionospheric monitoring using IGS data. In: 1993 IGS WORKSHOP, Berne. Proceedings... Berne: Beuther, G.; Brockmann, E., 1993. p. 351-360.

Wrasse, C. M.; Takahashi, H.; Medeiros, A. F. D.; Lima, L. M.; Taylor, M. J.; Gobbi, D.; Fechine, J. 2007. Determinaçao dos parâmetros de ondas de gravidade através da análise espectral de imagens de aeroluminescência. Revista Brasileira de Geofísica, v. 25, n. 3, p. 257-265.

Yamashita, C. S. Efeito das tempestades magnéticas intensas na ionosfera de baixa latitude. 1999. 75 f. Dissertação (Mestrado em Geofísica Espacial) - Instituto Nacional de Pesquisas Espaciais, São José dos Campos. 